The acts are symbolic of the need in modern societies to protect the privacy and confidentiality of individuals and at the same time ensure appropriate accountability of publicly funded services. At their best the acts should promote improved communication and management of records. The more that is published and the more easily and frequently patients have routine access to information about their health care, the less likely they are to need recourse to the law to get the information they seek.

Examples exist across the NHS of hospitals and practices routinely making information available to patients. These include general practices that invite patients to look at their own records or clinicians who routinely copy letters to patients, according to the policy of the Department of Health. ${ }^{8}$ Where healthcare professionals have developed such schemes, they and their patients have been rewarded with improved consultations, better understanding of treatment options, and the chance to correct mistakes in records.

In time the national programme for information technology will open "Healthspace," in which patients will be able to look at their records at their own convenience (www.healthspace.nhs.uk). This will be a major advance for patients and will go some way to creating more meaningful partnerships between patients and clinicians.

Many clinicians and health managers are unused to providing information about their performance, which is now open to scrutiny. Some may grudgingly seek to comply only with the letter of the law, and in doing so they may miss the wider potential of the acts to contribute to a patient centred NHS.

Legislation on its own cannot bring about a major change in culture. But it can act as a catalyst for improved performance in many ways. At its best, freedom of information should be a marker for openness and accountability in public services. It complements provisions for data protection for improving people's access to information about themselves, alongside the protection of their confidentiality and privacy. Both acts should help maintain progress to an NHS built on a "three-way partnership of respect, honesty and openness-between the NHS and the public, professionals and patients, and professionals and professionals."

\section{Barbara Meredith}

Epsom, Surrey KT17 4HQ (blmeredith@tiscali.co.uk)

Competing interests: BM chaired the working group on Copying Letters to Patients, which reported to the Department of Health in 2002. She is a member of the Patient Information Advisory Group, and of the Ethics Advisory Group of the Care Records Development Board. She is also part time project manager in the Patient Involvement Unit of the National Institute for Clinical Excellence. The views in this editorial are her personal views and not those of any organisation with which she is associated.

1 Protecting and using patient information. A manual for Caldicott guardProtecting and using patient information. A manual for Caldicott guardians. Department of Health, London NHS Executive, Leeds, 1999.
http://www.dh.gov.uk/assetRoot/04/06/81/36/04068136.pdf (accessed http://www. 27 Feb 05).

27 Feb 05).
Building the Information Core. Protecting and Using Confidential Building the Information Core. Protecting and Using Confidential
Patient Information. A Strategy for the NHS. Department of Health Information Policy Unit, London, 2001 http://www.publications. doh.gov.uk/ipu/confiden/strategyv7.pdf (accessed 27 Feb 05).

Confidentiality NHS Code of Practice, Department of Health, London, 2003. http://www.dh.gov.uk/assetRoot/04/06/92/54/04069254.pdf (accessed 27 Feb 05)

NHS Care Records Service. http://www.npfit.nhs.uk/programmes/nhscrs/

5 Data Protection Act 1998. www.hmso.gov.uk/acts/acts1998/ Data Protection Act 1998.

Freedom of Information Act 2000. www.hmso.gov.uk/acts/acts2000/ 20000036.htm (accessed 23 Feb 2005).

7 Statutory Instrument 2004 No. 3244. The Freedom of Information and Data Protection (Appropriate Limit and Fees) Regulations 2004 www.legislation.hmso.gov.uk/si/si2004/20043244.htm (accessed $23 \mathrm{Feb}$ 2005).

8 Copying Letters to Patients. Good Practice guidelines. Department of Health, London, 2003. http://www.dh.gov.uk/assetRoot/04/08/60/54/ 04086054.pdf

9 Learning from Bristol: the report of the public inquiry into children's heart surgery at the Bristol Roval Infirmary 1984-1995. London: Stationery Office, 2001. (CM 5207) www.bristol-inquiry.org.uk/final_report/ index.htm (accessed 23 Feb 2005).

\title{
Bat rabies in the United Kingdom
}

\author{
We need to put the risk in context
}

$\mathrm{U}$ ntil 2002 the United Kingdom had the luxury of being free of rabies. Worldwide as many as 70000 deaths occur per year, half of which are in children. ${ }^{1}$ In 2002 the first death from indigenously acquired rabies occurred in over 100 years. A naturalist and licensed bat handler died, not from classical rabies but from European bat lyssavirus type 2a (EBLV-2), acquired in Scotland. ${ }^{2}$ European bat lyssaviruses are closely related to the classical rabies virus. Hundreds of these infections have been confirmed in bats in continental Europe, mainly in Denmark, the Netherlands, Germany, Poland, France, and Spain. ${ }^{3}$ Most of these isolates were confirmed as EBLV-1 and predominantly associated with the serotine bat (Eptesicus serotinus) whereas EBLV-2 seems to be associated with Myotis species-principally the Daubenton's bats (Myotis daubentonii) and pond bats (Myotis dasycneme).

Passive surveillance for European bat lyssaviruses in bats in the United Kingdom over the past 18 years by the Veterinary Laboratories Agency has never discov- cases of EBLV-2, all isolated from Daubenton's bats. These have been found in various parts of EnglandNewhaven, Sussex, in 1996; Lancashire in 2002 and 2003; and Staines, Surrey, in 2004.-7 In addition preliminary data from a study to assess the presence of European bat lyssaviruses in bat populations in the United Kingdom confirmed the presence of antibodies to EBLV-2, but not virus, in 6-15\% of Daubenton's bats. ${ }^{8}$

With the evolving epidemiology of European bat lyssaviruses in the United Kingdom and its emergence as an increasingly important zoonotic infection, this is an opportune time to highlight current public health policy for the management of people who have had close exposure to bats. General practitioners and emergency departments may still be unaware of this risk of rabies from bat exposures in the United Kingdom and offer tetanus boosters or antibiotics to patients instead of rabies vaccination after they have been exposed. Any bat exposure will require expert assessment, and close cooperation is required between clinicians, laboratory experts, and human and animal 
public health experts. General practitioners and other clinicians need to be aware that anyone who has been scratched or bitten by a bat or whose eyes, broken skin, or mucous membrane have come in contact with bat saliva or neural tissue from a bat should be offered post-exposure rabies vaccination as soon as possible. Immunoglobulin may also be given if the bat is known or strongly suspected to be rabid. Detailed advice on post exposure prophylaxis is now available for clinicians in the revised Green Book's chapter on rabies and also advice on the public health management of a case of human rabies. ${ }^{9} 10$ The Department for Environment Food and Rural Affairs has also published a draft rabies contingency plan for consultation. ${ }^{11}$

The risk to public health needs to be put in context. Only licensed or volunteer bat handlers will routinely come into contact with bats. Current advice from the Department of Health says that all bat handlers should be vaccinated before exposure and should wear bite proof gloves when handling bats. Daubenton's bats are one of 16 species of bats in the United Kingdom and, unlike pipistrelles (Pipistrellus species) and long eared bats (Plecotis auritus), rarely roost in houses or come in contact with people. In the United Kingdom, pipistrelles and long eared bats have to date not been found to harbour European bat lyssaviruses. Therefore the likelihood of a member of the public coming into contact with an infected bat is small. Bats excreting European bat lyssaviruses in saliva are more than likely to show abnormal behaviour such as flying during daylight or being grounded or paralysed. A sick or injured bat should therefore never be handled by a member of the public but rather reported to either the Bat Conservation Trust (tel 0845 1300228), the Scottish Society for the Protection of Cruelty to Animals (tel 0870 7377722), or the relevant animal health divisional office.

We need to raise awareness in the general public of this small risk to human health without creating a fear of bats, which are a protected species under the Wildlife and Countryside Act 1981. Similarly, awareness among health professionals of current post exposure regimens also needs to be raised as rabies due to European bat lyssaviruses seems to be similar to classical rabies in being incurable but completely preventable. ${ }^{12}$

Alan Smith specialist registrar in public health medicine Jill Morris specialist registrar in public health medicine Natasha Crowcroft consultant epidemiologist

Health Protection Agency, Centre for Infections, London NW9 5HT (alan.smith@hpa.org.uk)

Competing interests: None declared.

1 Rupprecht CE, Hanlon CA, Hemachudha T. Rabies re-examined. Lancet Infect Dis 2002;2:327-43.

2 Fooks AR, McElhinney L, Pounder DJ, Finnegan CJ, Mansfield K, Johnson N, et al. Case report. Isolation of a European Bat Lyssavirus Type 2a from a fatal human case of rabies encephalitis. J Med Virol 2003; $71: 281-9$

3 Muller WW. Review of reported rabies case data in Europe to the WHO collaborating centre Tübingen from 1977 to 2000. Rabies Bull Eur 2000;24;11-9.

4 Whitby JE, Heaton PR, Black EM, Woodbridge M, McElhinney LM, Johnson P. First isolation of a rabies-related virus from a Daubenton's bat in the United Kingdom. Vet Rec 2000;147:385-8.

5 Johnson N, Selden D, Parsons G, Fooks AR. European bat lyssavirus type 2 in a bat in Lancashire. Vet Rec 2002;151:455-6.

6 Fooks AR, Selden D, Brookes SM, Johnson N, Martson DA, Joliffe TA, Fooks AR, Selden D, Brookes SM, Johnson N, Martson DA, Joliffe TA,
et al. Identification of a European bat lyssavirus type 2 ini a Daubenton's bat found in Lancashire. Vet Rec 2004;155:606-7.

7 Fooks AR, McElhinney LM, Marston DA, Selden D, Jolliffe TA, Wakeley $\mathrm{PR}$, et al. Identification of a European bat lyssavirus type 2 in a Daubenton's bat found in Staines, Surrey, UK. Vet Rec 2004;155:434-5.

8 Fooks A, Brookes S, Healy D, Smith GC, Aegerter J, Harris SL. Detection of antibodies to EBLV-2 in Daubenton's bats in the UK. Vet Rec 2004; 154:245-6.

9 Department of Health. Rabies. In: Immunisation against infectious disease. DOH;2004. www.dh.gov.uk/assetRoot/04/09/79/03/04097903.pdf (accessed 18 Jan 2005).

10 Health Protection Agency. The public health management of a suspected Health Protection Agency. The public health management of a suspected
case of human rabies. A standard operating procedure for communication \& action. www.hpa.org.uk/infections/topics_az/rabies/ final_rabies_SOP_301004.pdf (accessed 18 Jan 2005).

11 Department for Environment, Food, and Rural Affairs. Draft rabies contingency plan (RCP). www.defra.gov.uk/animalh/rabies/rabies_contingency/ index.htm (accessed 11 Jan 2005).

12 Hemachuda T, Laothamatas J, Rupprecht C. Human rabies: a disease of complex neuropathogenic mechanisms and diagnostic challenges. Lancet Neurol 2002;1:101-9.

\section{HIV testing}

Should no longer be accorded any special status

$\mathrm{B}$ efore highly active antiretroviral therapy (HAART) was introduced, the advantages to infected individuals of knowing their HIV status were minimal, and counselling before HIV testing was the recommended practice. ${ }^{1}$ This usually limited testing, by relying on people who were obviously at risk presenting themselves for testing. Such groups included injecting drug users and men who have sex with men and their sexual contacts. Targeting of these groups will become an increasingly less useful concept as HIV continues to spread into the population that is conventionally not at risk. Do we need to reconsider if routine voluntary counselling and testing is appropriate today?

Since 1991 heterosexual transmission of HIV has been the most common mode of transmission in the United Kingdom. ${ }^{2}$ Currently, nearly half of those infected heterosexually and a quarter of infected men who have sex with men in the United Kingdom are undiagnosed..$^{3}$ A quarter of newly diagnosed patients in the United Kingdom in 2002 were diagnosed late with serious immunosuppression. ${ }^{3}$ Unless further initiatives are undertaken the epidemic will worsen. Possible initiatives would be to lower thresholds for HIV testing by reducing the emphasis on pre-test counselling.

Reasons for low HIV testing rates and thus low detection rates include concerns about confidentiality, legal and insurance issues, self perceptions of low risk in those who would test positive, denial, dislike of counselling, and wishing to avoid anxiety when waiting for results. ${ }^{45}$ Fear and denial are the commonest obstacles to HIV testing among those acknowledging that they have been at risk. ${ }^{6}$

Additionally doctors' awareness of the effectiveness of early interventions is low and they may not encourage HIV testing. ${ }^{78}$ The most common reason, however, is lack of time for pre-test counselling, even in genitourinary medicine clinics. ${ }^{9}$ Average times for counselling are not less than 21 minutes with $18 \%$ of people requiring two sessions. ${ }^{1}$ 